\title{
Preparation of Astragalus membranaceus lectin and evaluation of its biological function
}

\author{
CHONG-ZHI BAI $^{1,2}$, JIAN-QING HAO $^{3}$, XU-LIANG HAO $^{1}$ and MA-LI FENG ${ }^{1}$ \\ ${ }^{1}$ Central Laboratory, Chinese Medicine Hospital of Shanxi Province, Taiyuan, Shanxi 030012; \\ ${ }^{2}$ CAS Key Laboratory of Pathogenic Microbiology and Immunology, Institute of Microbiology, \\ Chinese Academy of Sciences, Beijing 010010; ${ }^{3}$ Institute of Biotechnology, \\ School of Basic Medical Sciences, Shanxi Medical University, Taiyuan, Shanxi 030012, P.R. China
}

Received March 30, 2018; Accepted July 5, 2018

DOI: $10.3892 /$ br.2018.1132

\begin{abstract}
Astragalus membranaceus lectin (AML) was abstracted as a supposedly novel agglutinin of $67 \mathrm{kDa}$ from the seeds of Astragalus membranaceus. The seeds of Astragalus membranaceus were treated with acetate, ammonium sulfate precipitation, and purified by HiTrap SP XL ion column and Superdex G25 gel filtration chromatography to obtain the AML. AML contained $16.4 \%$ sugar, $70 \%$ polar amino acids and $\sim 30 \%$ hydrophobic amino acids. The AML exhibited agglutination activity toward human and animal erythrocytes, particularly human blood type $\mathrm{O}$ and rabbit erythrocytes. It also exhibited acid/alkali resistance and thermal denaturation above $64^{\circ} \mathrm{C}$. Compared with human normal liver HL-7702 cells, different concentrations of AML $(6.25,12.50,25.00$ and $50.00 \mu \mathrm{g} / \mathrm{ml})$ exhibited superior inhibitory effects on the growth of SGC-7901, HepG2 and H22 carcinoma cell lines, and displayed marked antibacterial effects on bacteria; the half maximal inhibitory concentration for B. dysenteriae, $S$. aureus and $E$. coli were 85.4, 80.2 and $65.3 \mu \mathrm{g} / \mathrm{ml}$, respectively.
\end{abstract}

\section{Introduction}

Astragalus membranaceus has been used historically in China for its apparent medicinal functions. Astragalus membranaceus in isolation, combined with other drugs or as a food supplement may promote health and immune balance (1). Modern pharmacological research has indicated that Astragalus membranaceus has various effects including in regulating the immune system, antioxidant function, in

Correspondence to: Dr Chong-Zhi Bai, Central Laboratory, Chinese Medicine Hospital of Shanxi Province, 16 Binghou Xijie, Taiyuan, Shanxi 030012, P.R. China

E-mail: 89453160@qq.com

Key words: Astragalus membranaceus, lectin, coagulation activity, antitumor, antibacterial promoting hematopoiesis and in regulating metabolism, among others, and that it could protect endothelial cells subjected to hypoxia-reperfusion by inhibiting lipid peroxidation and enhancing scavenging of oxygen free radicals (2). Studies have also suggested that Astragalus membranaceus may regulate the immune system, inhibit cell mitosis and inhibit the growth of mouse leukemia and lymphadenoma tumor cells by activating mouse B cells and macrophage cells $(2,3)$. The biological activity of Astragalus membranaceus may be due to the functions of its composite proteins, polysaccharides and flavonoids. However, there are few studies on the biological activities of the putative functional proteins of Astragalus membranaceus, and its mechanism of action remains unclear. Therefore, it is of interest to study the effects of proteins extracted from Astragalus membranaceus in terms of potential Antitumor and anti-antibacterial mechanisms.

Lectin has various biological functions, which have become increasingly recognized by previous studies (4-8). It is a type of non-immune glycoprotein that can interact with carbohydrate in a reversible and specific manner. Lectin contains a variable amino acid sequence, and is widely distributed in microbes, virus' and plants (9). The specificity of lectin extends not only to sugar-binding activity but also to function, structure and tissue expression (10). Certain studies have revealed that lectin exhibits various biological activities, including insecticidal activity (4), antifungal action (5), Antitumor effects (6), antivirus action (7) and immunomodulatory effects (8). Furthermore, it has been identified that lectin could be applied in host defence and in the treatment of various diseases including cancer $(11,12)$.

At present, to the best of our knowledge, there are no reports on the abstraction or functions of lectin from the seeds of Astragalus membranaceus. Therefore, in the present study, Astragalus membranaceus lectin (AML) was abstracted, purified and resolved, and its biological activities examined to provide experimental support for the application of Astragalus membranaceus as a therapeutic remedy.

\section{Materials and methods}

Materials and samples. The seeds of Astragalus membranaceus were obtained from Shanxi Academy of Agricultural 
Sciences (Taiyuan, China). Human blood samples (1 ml each of two type A samples, two type B samples, two type AB samples and two type $\mathrm{O}$; all 8 subjects were male, aged 20-40 years old and disease-free) were collected by the Chinese Medicine Hospital of Shanxi Province (Taiyuan, China). Experimental animals were supplied by the animal laboratory centre of Shanxi Medical University (Taiyuan, China). A total of 5 male Japanese White rabbits (8 months old, weight 4-5 kg), 10 C57 male mice (5 weeks old, weight 20-22g) and 10 SD male rats (2.5 months old, weight 350-380 g) were used to collect blood samples, and were housed in a specific pathogen-free (SPF) room under controlled temperature and humidity. A 12-h light/dark cycle was maintained. A HiTrap SP XL anion exchange column and Superdex G25 gel filtration column were purchased from GE Healthcare (Uppsala, Sweden). Fetal bovine serum (FBS) and RPMI-1640 medium were sourced from Sigma-Aldrich (Merck KGaA, Darmstadt, Germany). All solvents used in high-performance liquid chromatography were of chromatography grade, and all other reagents were of the highest purity available.

All subjects whose blood was collected gave sign informed consent for the use of their samples for research purposes. All human and animal protocols were performed according to the Guide for the Care and Use of Laboratory Animals (13) and approved by the Ethics Committees of the Chinese Medicine Hospital of Shanxi Province (Taiyuan, China) and the Chinese Academy of Medical Sciences (Beijing, China).

Extraction and purification of AML. The seeds of Astragalus membranaceus were ground and treated with acetate buffer (pH 5.0) for $24 \mathrm{~h}$ at $4^{\circ} \mathrm{C}$, and then centrifuged at $10,000 \mathrm{x} \mathrm{g}$ and $4^{\circ} \mathrm{C}$ for $30 \mathrm{~min}$. $\left(\mathrm{NH}_{4}\right)_{2} \mathrm{SO}_{4}$ was added into the supernatant to $80 \%$ saturation and stirred for $4 \mathrm{~h}$ at $4^{\circ} \mathrm{C}$, followed by centrifugation at $12,000 \mathrm{xg}$ and $4^{\circ} \mathrm{C}$ for $30 \mathrm{~min}$. The supernatant was discarded and the remaining pellet was precipitated after dissolving with $20 \mathrm{mM}$ Tris- $\mathrm{HCl}$ buffer (pH 7.0), and then centrifuged at $10,000 \times \mathrm{g}$ and $4^{\circ} \mathrm{C}$ for $30 \mathrm{~min}$. The supernatant was used to confirm protein content and hemagglutination activity. A two-step chromatography method was used to collect AML. Crude astragalus seed extracts dissolved in $2 \mathrm{ml} 20 \mathrm{mM}$ Tris- $\mathrm{HCl}$ buffer ( $\mathrm{pH}$ 7.0) were loaded onto a HiTrap SP XL column, then loaded onto a Superdex G-25 column and eluted by $0.5 \mathrm{M} \mathrm{NaCl}$ in $20 \mathrm{mM}$ phosphate-buffered saline (PBS), at a flow rate of $0.5 \mathrm{ml} / \mathrm{min}$, in an $\mathrm{AKTA}^{\mathrm{TM}}$ Explore protein purification system (GE Healthcare) at room temperature. The bicinchoninic acid assay method was used to detect the level of AML.

Polyacrylamide gel electrophoresis (SDS-PAGE). According to the method reported by Laemmli (14), the separation gel and spacer gel concentrations were 12.5 and $4.0 \%$ respectively. A total of $15 \mu 1$ protein was loaded per lane. The gel was stained with Coomassie brilliant blue R250 for $1 \mathrm{~h}$ at room temperature, and then the formula weight of the protein band was confirmed by a Gel imaging analysis system (Bio-Rad Gel DocXR with Quantity One v4.62 software; Bio-Rad Laboratories, Inc., Hercules, CA, USA).

Analysis of coagulation activity of AML. Rabbit blood $(0.5 \mathrm{ml})$ was collected via the auricular vein, and mouse and rat blood $(0.5 \mathrm{ml})$ were collected via orbital puncture. The coagulation activity of AML was detected in microtitration $\mathrm{V}$ plates $(25 \mu \mathrm{l})$. The AML $(1 \mathrm{mg} / \mathrm{ml})$ was mixed with $25 \mu \mathrm{l}$ of $2 \%$ whole blood in normal saline, and then incubated at room temperature until the cells were all deposited in the wells of the blank group (blood samples not mixed with AML). Agglutination activity was determined from the detection of agglutinated erythrocytes by naked eye, and $1 / 2^{n}$ (with $n$ being the number of wells exhibiting an agglutination reaction) was presented as the agglutination titer (15).

Detection of PH and thermal stability of AML. To detect the influence of $\mathrm{pH}$ on the AML, AML was dissolved in $\mathrm{Cl}$ at $\mathrm{pH}$ 2.4-3.0 and $\mathrm{NaOH}$ at $\mathrm{pH}$ 11.7-12.2. Incubation was performed for $30 \mathrm{~min}$ at room temperature to neutralize the solution, and coagulation activity was detected by the above method. To detect the thermal stability of AML, the protein $(1 \mathrm{mg} / \mathrm{ml})$ was incubated at different temperatures $\left(25-80^{\circ} \mathrm{C}\right)$ for $30 \mathrm{~min}$, then placed immediately on ice for $5 \mathrm{~min}$, and its coagulation activity was detected.

Detection of metal ion stability of AML. A 20 mM EDTA-AML solution $(1 \mathrm{mg} / \mathrm{ml}$ AML initial concentration) was dialyzed and its coagulation activity was detected. Following dialysis, the solution was added into $10 \mathrm{mM} \mathrm{Cu}^{2+}, \mathrm{Mg}^{2+}$ or $\mathrm{Zn}^{2+}$, and its coagulation activity was detected.

Detection of sugar content of AML. The sugar content of $1 \mathrm{mg} / \mathrm{ml} \mathrm{AML}$ was detected by the phenol-sulfuric acid method (16), and its optical density (OD) value was measured at $490 \mathrm{~nm}$. Anhydrous glucose was chosen as the standard. A total of $0.5 \mathrm{ml}$ sample containing 2-25 $\mu \mathrm{g}$ sugar was selected, mixed with $0.3 \mathrm{ml} 5 \%$ phenol solution followed by $1.8 \mathrm{ml}$ concentrated sulfuric acid, and its OD value was detected at $490 \mathrm{~nm}$. Sugar content of AML was determined from the standard curve. The sugar content was the abscissa, and the OD value the ordinate.

Detection of amino acid content of AML. A total of $1 \mathrm{mg} / \mathrm{ml}$ AML was dissolved in $6 \mathrm{M} \mathrm{HCl}$, hydrolyzed at $100^{\circ} \mathrm{C}$ for $24 \mathrm{~h}$, and analyzed using a Germany Manmerbor A300 Automatic amino acid analyser (MembraPure GmbH, Hennigsdorf, Germany).

Antibacterial activity of AML. Serial dilution of liquid nutrient medium was conducted to detect the antibacterial activity of AML, and the medial lethal dose of AML against bacteria was screened according to preliminary results (unpublished). Using four sterile tubes, $1 \mathrm{ml}$ broth culture (tryptone $10 \mathrm{~g} / \mathrm{l}$, yeast extract $5 \mathrm{~g} / \mathrm{l}, \mathrm{NaCl} 10 \mathrm{~g} / \mathrm{l}$ ) and $1 \mathrm{ml}$ AML solution were mixed in one tube, from which $1 \mathrm{ml}$ solution was isolated added into the second tube until the fourth tube; the final concentrations of AML were 25,50,100 and $200 \mu \mathrm{g} / \mathrm{ml}$. A tube containing $1 \mathrm{ml}$ broth culture and $1 \mathrm{ml}$ aseptic water was used as a control. Into each tube $50 \mu \mathrm{l}$ bacterial liquid $\left(10^{6}\right.$ cells $/ \mathrm{ml}$ in broth culture) containing Bacillus dysenteriae (B. dysenteriae), Staphylococcus aureus (S. aureus) or Escherichia coli (E. coli) (all from China General Microbiological Culture Collection Center, Beijing, China) was added, mixed and cultured in a $37^{\circ} \mathrm{C}$ incubator. A sixth tube was designated a 
A

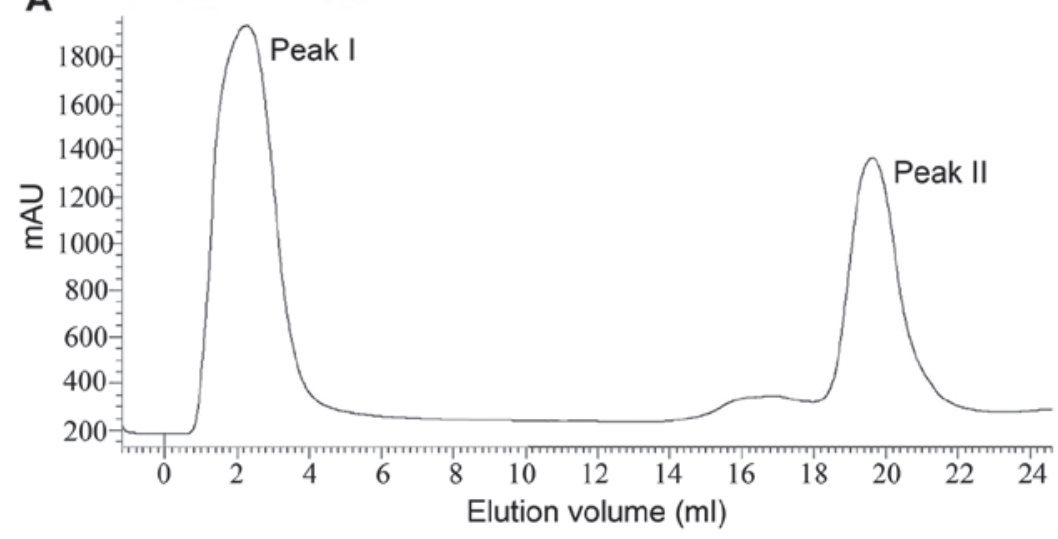

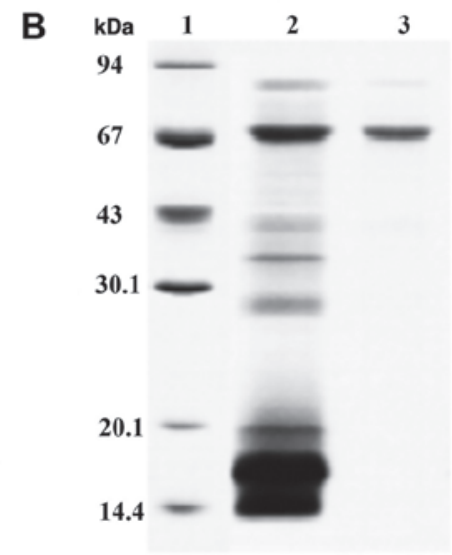

Figure 1. (A) Profile of elution in purification of AML. (B) Results of SDS-PAGE. Lane 1, molecular weight marker; lane 2, crude astragalus seed extracts; lane 3, peak II from Chromatography. AML, Astragalus membranaceus lectin.

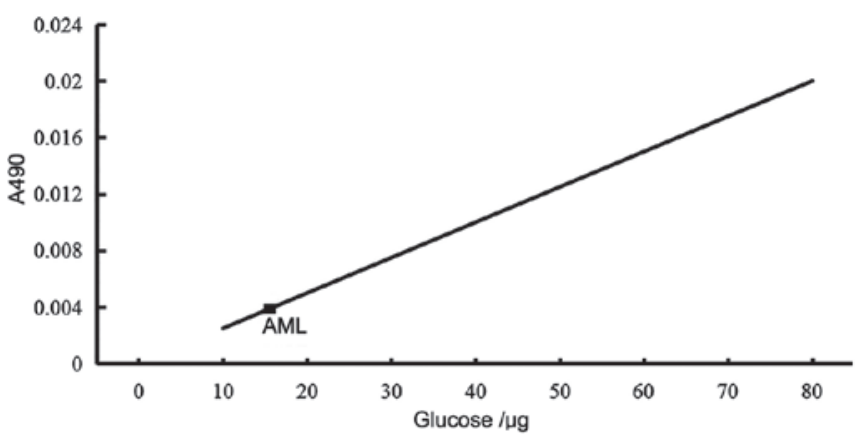

Figure 2. Sugar content of AML. AML, Astragalus membranaceus lectin.

zero tube, into which $1 \mathrm{ml}$ broth culture, $1 \mathrm{ml}$ aseptic water and $50 \mu \mathrm{l}$ normal saline were added. After $24 \mathrm{~h}$, the absorbance value of each tube was observed at $600 \mathrm{~nm}$. Mean absorbance was calculated from three replicate measurements. The half maximal inhibitory concentration $\left(\mathrm{IC}_{50}\right)$ of $\mathrm{AML}$ to each test bacteria was calculated according to the formula $\mathrm{IC}_{50}=\mathrm{Ilg}-1$ $\{\mathrm{Xm}-\mathrm{I}[\Sigma \mathrm{P}-(3-\mathrm{Pm}-\mathrm{Pn}) / 4]\}$ (17), where Xm: the logarithmic value of the maximum concentration; i: the logarithmic value of the ratio of maximum dose to current dose; $\Sigma \mathrm{P}$ : the sum of the growth inhibition rate of each group; Pm: the maximum positive reaction rate; $\mathrm{Pn}$ : the minimum positive reaction rate.

Antitumor activity of AML. A Cell Counting Kit-8 (CCK-8) assay (Dojindo Molecular Technologies, Inc., Kumamoto, Japan) was used to analyze the antitumor activity of AML. SGC-7901, HepG2, H22 and HL-7702 cells (BeNa Culture Collection, Beijing, China) in logarithmic growth phase were selected to prepare cell suspensions of $1 \times 10^{6} \mathrm{cell} / \mathrm{ml}$, which were seeded into 96-well plates, with three repeats per cell sample. The cells were cultured in a $5 \% \mathrm{CO}_{2}, 37^{\circ} \mathrm{C}$ incubator for $2 \mathrm{~h}$, after which PBS was added with different concentrations of AML $(6.25,12.50,25.00$ and $50.00 \mu \mathrm{g} / \mathrm{ml})$. The cells were further cultured in the $37^{\circ} \mathrm{C}, 5 \% \mathrm{CO}_{2}$ incubator for 12 , 20 and $24 \mathrm{~h}$ respectively, after which $10 \mu \mathrm{l}$ CCK- 8 was added and cells were incubated for another $4 \mathrm{~h}$ prior to measurement at $570 \mathrm{~nm}$. The $\mathrm{IC}_{50}$ of AML to each cell line was calculated according to the above formula.

\section{Results}

Abstraction and identification of AML. Following rough abstract, ammonium sulfate precipitation and dialysis, the crude proteins were purified by an AKTA Explore system with HiTrap SP XL and Superdex G25 columns. Proteins were obtained weighted $67 \mathrm{kDa}$ by SDS-PAGE (Fig. 1).

Detection of agglutination titer. The hemagglutination effect of AML on human and animal erythrocytes was as follows: Human (A type), 1/29; human (B type), 1/2 $1 / 2^{8}$; human (O type), $1 / 2^{10}$; rat, $1 / 2^{9}$; mouse, $1 / 2^{8}$; rabbit, $1 / 2^{10}$. At the initial concentration of $1 \mathrm{mg} / \mathrm{ml}, 1 / 2^{8}=3.91 \mu \mathrm{g} / \mathrm{ml}$, $1 / 2^{9}=1.95 \mu \mathrm{g} / \mathrm{ml}$ and $1 / 2^{10}=0.97 \mu \mathrm{g} / \mathrm{ml}$ (data not shown).

PH and thermal stability of AML. The AML exhibited minor thermal stability: When it was heated to $64^{\circ} \mathrm{C}$, it exhibited normal coagulation activity; while the temperature increase from 64 to $70^{\circ} \mathrm{C}$ caused a marked decline in activity, and activity was no longer apparent at $80^{\circ} \mathrm{C}$. By contrast, AML exhibited considerable $\mathrm{pH}$ stability, with normal coagulation activity observed at $\mathrm{pH} 2-13$. At $\mathrm{pH} 0-1$, activity declined to $\sim 50 \%$ and at $\mathrm{pH} 14$ was undetectable (data not shown).

Influence of metal ions on the agglutination activity of AML. Following dialysis of AML using $20 \mathrm{mM}$ EDTA, no apparent changes were observed in its agglutination activity. Its activity was also unchanged following the addition of $20 \mathrm{mM} \mathrm{Cu}^{2+}$, $\mathrm{Mg}^{2+}$ or $\mathrm{Zn}^{2+}$; the titers of agglutination activity were $1 / 2^{10}$ for $\mathrm{Cu}^{2+}, 1 / 2^{10}$ for $\mathrm{Mg}^{2+}$ and $1 / 2^{9}$ for $\mathrm{Zn}^{2+}$. Initial concentration was $1 \mathrm{mg} / \mathrm{ml} ; 1 / 2^{9}=1.95 \mu \mathrm{g} / \mathrm{ml}$ and $1 / 2^{10}=0.97 \mu \mathrm{g} / \mathrm{ml}$. Therefore, the agglutination activity of AML had no apparent association with the presence of the three metal ions (data not shown).

Sugar content of AML. The sugar content of AML was determined to be $16.4 \%$ (Fig. 2).

Amino acid content of AML. AML contained 15 types of amino acid, among which the majority were charged and polar amino acids, accounting for $\sim 70 \%$, while the remaining $30 \%$ were hydrophobic amino acids. The content of Asp/Asn and 


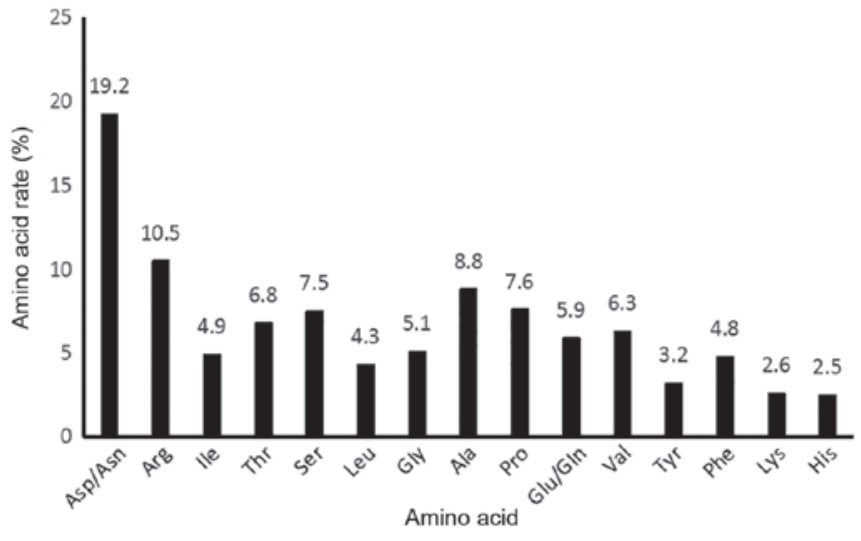

Figure 3. Amino acid content of Astragalus membranaceus lectin.

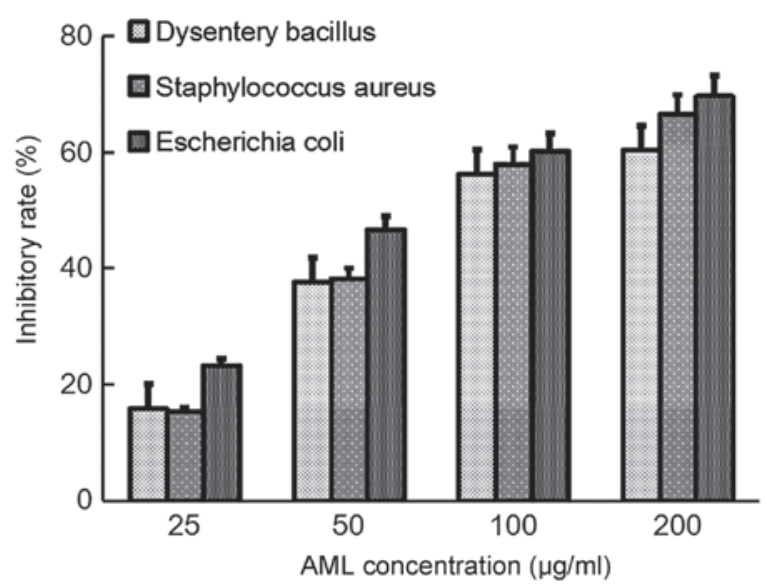

Figure 4. Antibacterial activity of AML. AML, Astragalus membranaceus lectin.

Arg, as amino acids associated with immunity (18), was relatively high, nearing $30 \%$ (Fig. 3).

Antibacterial activity of AML. The inhibition ratios of different concentrations of AML indicated a dose-dependent effect on the three test bacteria. The $\mathrm{IC}_{50}$ for $B$. dysenteriae, S. aureus and E. coli were 85.4, 80.2 and $65.3 \mu \mathrm{g} / \mathrm{ml}$, respectively (Fig. 4).

Antitumor activity of AML. The inhibition ratios of different concentrations of AML suggested a dose-dependent effect on the three tumor cell lines and normal liver cells. The $\mathrm{IC}_{50} \mathrm{~s}$ for SGC-7901, HepG2, H22 and HL-7702 were 19.6, 19.6, 15.5 and $45.1 \mu \mathrm{g} / \mathrm{ml}$, respectively. Therefore, compared with its effect on the tumor cells, AML exhibited lower cytotoxicity against normal cells, which confirmed that AML had inhibitory effects on the three tumor cell lines (Fig. 5).

\section{Discussion}

In the present study, AML was extracted, separated and purified from the seeds of Astragalus membranaceus via buffer extraction, ammonium sulfate precipitation, dialysis and laminar flow analysis with HiTrap SP XL ion exchange and Superdex G25 solvent resistant columns. Its molecular weight was analyzed using SDS-PAGE and determined to be $\sim 67 \mathrm{kDa}$; furthermore,

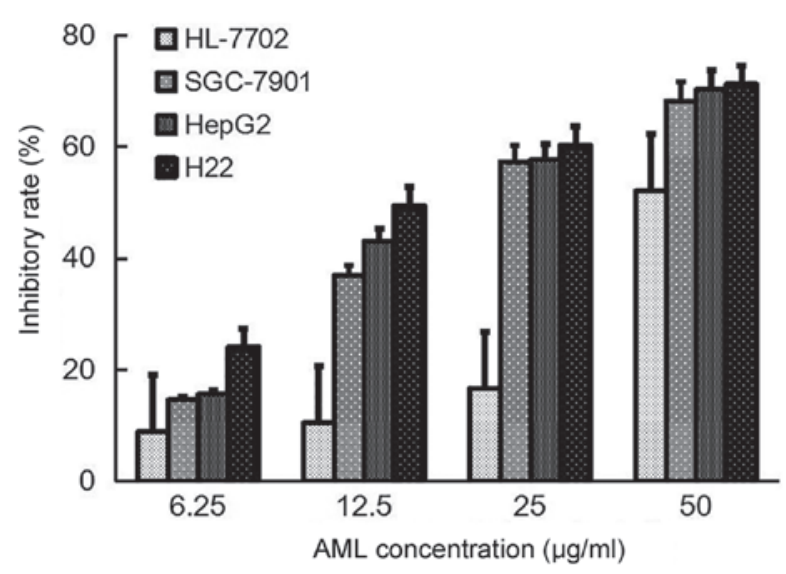

Figure 5. Antitumor cell activity of AML. AML, Astragalus membranaceus lectin.

its sugar content was $16.4 \%$ which differed from that reported previously of $10.7 \%$ (19) and it contained 15 types of amino acid, of which the majority were charged and polar amino acids $(\sim 70 \%)$, with the remaining portion being hydrophobic amino acids $(\sim 30 \%)$. The content of Asp/Asn and Arg, associated with immunity, was relatively high and nearing $30 \%$. The properties of AML including coagulation activity, $\mathrm{pH}$ and temperature as well as metal ion stability were further analyzed, and its antibacterial and Antitumor activities were studied. Results indicated that AML exerted stimulatory effects on the agglutination of 4 human blood types and mouse, rat and rabbit erythrocytes, particularly on human blood type $\mathrm{O}$ and rabbit erythrocytes. The AML exhibited resistance to three types of metal iron, and its thermal denaturation temperature was over $64^{\circ} \mathrm{C}$. AML had preserved total hemagglutination activity at $\mathrm{pH} 2-13$, despite previous studies indicating that hemagglutination activity gradually weakened when $\mathrm{pH}>9(20,21)$; the current data indicates that this novel lectin has a more stable $\mathrm{pH}$ than previously proposed, as a suitable precondition for later drug development. Additionally, AML exhibited inhibitory effects on three test bacteria, including $B$. dysenteriae, $S$. Aureus and $E$. coli, for which the corresponding $\mathrm{IC}_{50 \mathrm{~s}}$ were all $<100 \mu \mathrm{g} / \mathrm{ml}$. AML also exerted inhibitory effects on the growth of SGC-7901, HepG2 and H22 cells, contrasting to its less toxic effect on HL-7702 cells, although its antitumor mechanism was unclear and requires further study.

\section{Acknowledgements}

Not applicable.

\section{Funding}

The current work was supported by the Natural Science Foundation of Shanxi Province (grant no. 20170110) and the Scientific Research Project of the Health Planning Committee of Shanxi (grant no. 201601083).

\section{Availability of data and materials}

All data described in the article are available upon request from the corresponding author. 


\section{Authors' contributions}

CZB contributed to conception and design of the study; to acquisition, analysis and interpretation of the data; and to drafting of the manuscript. JQH, XLH and MLF each contributed to acquisition of the data and to revision of the manuscript. MLF contributed to analysis and interpretation of the data as well as to revision of the manuscript.

\section{Ethics approval and consent to participate}

The study protocol complied with the Guide for the Care and Use of Laboratory Animals and was approved by the Ethics Committees of the Chinese Medicine Hospital of Shanxi Province (Taiyuan, China). Written informed consent was obtained from all subjects.

\section{Consent for publication}

All participants involved in this research agreed to the publication of any associated data and accompanying images.

\section{Competing interests}

The authors declare that they have no competing interests.

\section{References}

1. Jin M, Zhao K, Huang Q and Shang P: Structural features and biological activities of the polysaccharides from Astragalus membranaceus. Int J Biol Macromol 64: 257-266, 2014.

2. Shao BM, Xu W, Dai H, Tu P, Li Z and Gao XM: A study on the immune receptors for polysaccharides from the roots of Astragalus membranaceus, a Chinese medicinal herb. Biochem Biophys Res Commun 320: 1103-1111, 2004.

3. Cho WC and Leung KN: In vitro and in vivo Antitumor effects of Astragalus membranaceus. Cancer Lett 252: 43-54, 2007.

4. Vandenborre G, Smagghe G and Van Damme EJ: Plant lectins as defense proteins against phytophagous insects. Phytochemistry 72: 1538-1550, 2011.

5. de Vasconcelos MA, Cunha CO, Arruda FV, Carneiro VA, Mercante FM, do Nascimento Neto LG, de Sousa GS, Rocha BA, Teixeira EH, Cavada BS, et al: Lectin from Canavalia brasiliensis seeds $(\mathrm{Con} \mathrm{Br})$ is a valuable biotechnological tool to stimulate the growth of Rhizobium tropici in vitro. Molecules 17: 5244-5254, 2012.
6. Balzarini J, Neyts J, Schols D, Hosoya M, Van Damme E, Peumans W and De Clercq E: The mannose-specific plant lectins from Cymbidium hybrid and Epipactis helleborine and the (N-acetylglucosamine)n-specific plant lectin from Urtica dioica are potent and selective inhibitors of human immunodeficiency virus and cytomegalovirus replication in vitro. Antiviral Res 18: 191-207, 1992.

7. Zuo Z, Fan H, Wang X, Zhou W and Li L: Purification and characterization of a novel plant lectin from Pinellia ternata with antineoplastic activity. Springerplus 1: 13, 2012.

8. Peumans WJ and Van Damme EJ: Lectins as plant defense proteins. Plant Physiol 109: 347-352, 1995.

9. Kaltner H, García Caballero G, Ludwig AK, Manning JC and Gabius HJ: From glycophenotyping by (plant) lectin histochemistry to defining functionality of glycans by pairing with endogenous lectins. Histochem Cell Biol 149: 547-568, 2018.

10. Liu XQ, Wu H, Yu HL, Zhao TF, Pan YZ and Shi RJ: Purification of a lectin from Arisaema erubescens (Wall.) schott and its proinflammatory effects. Molecules 16: 9480-9494, 201111.

11. Ye XY, Ng TB, Tsang PW and Wang J: Isolation of a homodimeric lectin with antifungal and antiviral activities from red kidney bean (Phaseolus vulgaris) seeds. J Protein Chem 20: 367-375, 2001.

12. Heinrich EL, Welty LA, Banner LR and Oppenheimer SB: Direct targeting of cancer cells: A multiparameter approach. Acta Histochem 107: 335-344, 2005.

13. Bruce A: Guide for the Care and Use of Laboratory Animals. National Academies Press, Washington, pp85-123, 1996.

14. Laemmli UK: Cleavage of structural proteins during the assembly of the head of bacteriophage T4. Nature 227: 680-685, 1970.

15. Qin XZ, Yang XP and Chen J: Hemagglutinins of higher fungi in Altay. Xinjiang Nongye Kexue 53: 142-148, 2016 (In Chinese).

16. Dubois M, Gilles KA, Hamilton JK, Rebers PA and Smith F: Colorimetric method for determination of sugars and related substances. Anal Chem 28: 350-356, 1956.

17. Chou TC: The median-effect principle and the combination index for quantitation of synergism and antagonism. In: Synergism and Antagonism in Chemotherapy. Chou TC and Rideout DC (eds). Academic Press, San Diego, CA, pp61-102, 1991.

18. Barbul A, Sisto DA, Wasserkrug HL and Efron G: Arginine stimulates lymphocyte immune response in healthy human beings. Surgery 90: 244-251, 1981.

19. Zhu LF and Yan QJ, Jiang ZQ and Huang LH: Isolation and purification of a lectin from roots of Astragalus membranaceus. Chin Tradit Herbal Drugs 41: 714-717, 2010.

20. Kaur A, Singh J, Kamboj SS, Sexana AK, Pandita RM and Shamnugavel M: Isolation of an N-acetyl-D-glucosamine specific lectin from the rhizomes of Arundo donax with antiproliferative activity. Phytochemistry 66: 1933-1940, 2005.

21. Vaz AF, Costa RM, Melo AM, Oliva ML, Santana LA, Silva-Lucca RA, Coelho LC and Correia MT: Biocontrol of Fusarium species by a novel lectin with low ecotoxicity isolated from Sebastiania jacobinensis. Food Chem 119: 1507-1513, 2010. 